\title{
Undergraduate Research in the Time of COVID-19: A Remote Imaging Protocol for Physically Distanced Students Studying Wildlife.
}

\author{
Manuela Tripepi \\ Thomas Jefferson University \\ Tobias Landberg \\ The Amphibian Foundation
}

Follow this and additional works at: https://jdc.jefferson.edu/jclsfp

Part of the Biology Commons

Let us know how access to this document benefits you

\section{Recommended Citation}

Tripepi, Manuela and Landberg, Tobias, "Undergraduate Research in the Time of COVID-19: A Remote Imaging Protocol for Physically Distanced Students Studying Wildlife." (2021). College of Life Sciences Faculty Papers. Paper 10.

https://jdc.jefferson.edu/jclsfp/10

This Article is brought to you for free and open access by the Jefferson Digital Commons. The Jefferson Digital Commons is a service of Thomas Jefferson University's Center for Teaching and Learning (CTL). The Commons is a showcase for Jefferson books and journals, peer-reviewed scholarly publications, unique historical collections from the University archives, and teaching tools. The Jefferson Digital Commons allows researchers and interested readers anywhere in the world to learn about and keep up to date with Jefferson scholarship. This article has been accepted for inclusion in College of Life Sciences Faculty Papers by an authorized administrator of the Jefferson Digital Commons. For more information, please contact: JeffersonDigitalCommons@jefferson.edu. 


\title{
Undergraduate Research in the Time of COVID-19: A Remote Imaging Protocol for Physically Distanced Students Studying Wild life ${ }^{\dagger}$
}

\author{
Manuela Tripepi ${ }^{1 *}$ and Tobias Landberg ${ }^{2}$ \\ 'Thomas Jefferson University, College of Life Sciences, Philadelphia, PA 19144; \\ ${ }^{2}$ The Amphibian Foundation, Atlanta, GA 30342
}

The COVID-19 pandemic has shuttered many university research labs because campuses are closed, and faculty and students lack productive ways of working remotely. This presents major difficulties for students who need research opportunities to fulfill their intellectual growth potential and their undergraduate research and thesis requirements. Without research experiences, undergraduates may be less competitive for future jobs and graduate programs. Similarly, faculty need research avenues to advance their academic careers while maintaining physically distant protocols. We outline here a budget-friendly, COVID-friendly, adaptable protocol that aims to introduce students to the wildlife research opportunities surrounding their campus or home through observation and literature research. Student researchers learn the scientific method by getting first-hand experience with an original research project. The pedagogical goals include designing a study: defining a question or proposing a hypothesis, collecting, organizing, and analyzing data, and sharing results in the form of posters, theses, informal educational materials, and scientific publications. This protocol is flexible to allow for different budgets, opportunities, and constraints. The researchers monitor different locations using trail cameras to determine which species are present around campus or even students' homes. During the COVID-19 pandemic, when it is likely there will be few in-person meetings, this protocol offers students the opportunity to carry out research with limited or no in-person meetings, and it can be run remotely by sharing the data collected. In this paper, we provide instructions, details, and student handouts for instructors to help implement this research project.

\section{INTRODUGTION}

The spread of COVID-19 has greatly impacted the way research can be conducted with students $(I-3)$. Here we present a protocol for faculty that allows undergraduate students to perform research and to collect and analyze data without requiring work in a laboratory or in-person meetings.

This basic protocol facilitates learning the scientific method by introducing undergraduate biology students to the study of wildlife in their local environments on college campuses or near their homes. During the project, students use remote imaging technology (trail cameras) to document animal species present in their study sites. Further, they can

*Corresponding author. Mailing address:Thomas Jefferson University, East Falls Campus, College of Life Sciences, 4201 Henry Ave., Philadelphia, PA 19I44. Phone: 2I5-95I-0424.E-mail: Manuela.Tripepi@ jefferson.edu.

Received: 13 October 2020, Accepted: 4 January 202 I, Published: 3I March 2021

†Supplemental materials available at http://asmscience.org/jmbe analyze the animals' behavior and activity patterns that may be affected by factors such as temperature, season, time of day, and moon phases. After collecting the data, students can present their work at the end of the semester in the form of a poster or computer presentation to practice how to clearly communicate their research to different audiences.

This protocol is suitable for short-term studies that last a single semester, but the value of the data would increase if applied to a long-term ecological research program because changes over greater time periods could be detected, such as patterns of ecological succession, habitat degradation or restoration, and climate change. To take the project a step further, students and faculty can customize the protocol to suit their local needs by adapting it to different research questions. Connecting the wildlife observed to common biodiversity threats caused by human colonization, urbanization, environmental conditions, and global climate change are some of the many options that may suit the goals of researchers (4). While the majority of college campuses are inclined to include sustainability in their new planning, the consideration for wildlife and wildlife habitat is lower in priority for these institutions, and this project may empower students and focus their attention on ways they can contribute to their community's environmental

(C)2021 Author(s). Published by the American Society for Microbiology. This is an Open Access article distributed under the terms of the Creative Commons Attribution-Noncommercial-NoDerivatives 4.0 Internationa license (https://creativecommons.org/licenses/by-nc-nd/4.0/ and https://creativecommons.org/licenses/by-nc-nd/4.0/legalcode), which grants the public the nonexclusive right to copy, distribute, or display the published work. 


\section{TRIPEPI AND LANDBERG: PHYSICALIY DISTANT REMOTE IMAGING RESEARCH}

goals by providing scientific data to help inform school administration decisions (5).

The benefits of participating in student research are widespread and well-documented. Our experience mentoring students strongly indicates that the more a student contributes to research, the more engaged they are in the process. This improves outcomes for student learning, responsibility, confidence, and ultimately transfers to other areas of their academic and intellectual success (6-10).

\section{PROCEDURE}

\section{Materials}

Based on the instructor's budget, the project can be conducted with one or more cameras to allow monitoring of different locations. We use the CamPark T80 trail camera, a budget-friendly camera that offers night vision and motionactivated recordings (Appendix I). The cameras were tied to a tree and secured by a Master lock cable, at a height of around 5 feet to ensure the largest capture area and easy access to change the memory card. We installed a sign near the camera that alerted the public to the ongoing research (Fig. I). The camera was set at 20 -second recording durations for videos and 10 -second time intervals for the trigger speed. The passive infrared (PIR) which detects heat and motion intervals was also set at 10 seconds. Cameras were equipped with a memory card SanDisk 32GB and Energizer lithium batteries. The SanDisk cards were retrieved and swapped every two weeks. We used a drone (Mavic Mini) to take aerial photos of the area surrounding the camera location.

\section{Experimental steps and student tasks}

A survey of campus locations or nearby areas is suggested to choose the most appropriate sites for camera trapping. We selected locations that had low foot traffic and offered a relatively undisturbed environment for animals. We made sure that no small branches were in the way of the camera view to avoid wind-driven motion-triggered recordings. Examples of camera set-ups are provided in Figure 2.

Students are responsible for checking and swapping the SD card regularly and cataloging the images, identifying animals, and entering data. Data can be shared on shared servers such as Google drive or Dropbox. Students may be able to contribute to the three main phases of the project including design, implementation, and presentation. The design phase includes asking biological questions, conducting background research, formulating a specific research question, defining research goals or formulating a scientific hypothesis, and funding the work through grant applications. The implementation phase includes collecting, processing, organizing, and analyzing data. This phase also includes troubleshooting, revising protocols, and editing and quality controlling the data. The presentation phase includes

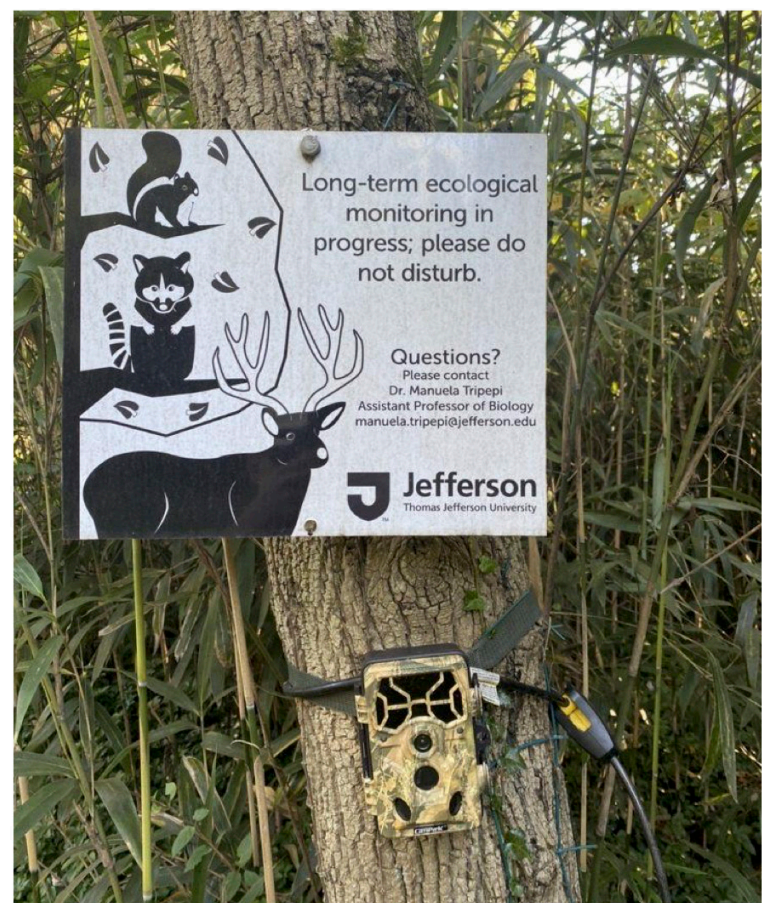

FIGURE I. Camera set-up.The camera is secured to a tree by a strap and a master lock. A metal sign alerts passersby of the research being conducted at the site and provides contact information for the principal investigator.

creating figures, graphs, tables, illustrations, or other ways of visualizing results and communicating research to different audiences and in varying venues.

Students experience working collaboratively using listening, time management, and communication skills (Appendix I). Goal setting, taking responsibility for research duties and obligations, and practicing teamwork help build confidence and student identity in constructive and positive ways in a supportive lab environment. Weekly meetings between students and faculty or research lab meetings provide structure and support for students while giving them time to conduct their research between meetings.

\section{Safety issues}

The activities in this paper do not present safety issues. We recommend checking with the Institutional Animal Care and Use Committee (IACUC) to verify whether IACUC approval is necessary to start the research. Further, we recommend contacting your Department of Safety and Security for guidance on matters such as the installation and location of the camera and privacy of passersby. We posted signs to indicate research was in progress in each location we installed a camera (Fig. I).

\section{CONCLUSION}

The project started at Jefferson University at the end of January 2020. At the end of the semester, students pre- 


\section{TRIPEPI AND LANDBERG: PHYSICALLY DISTANT REMOTE IMAGING RESEARCH}
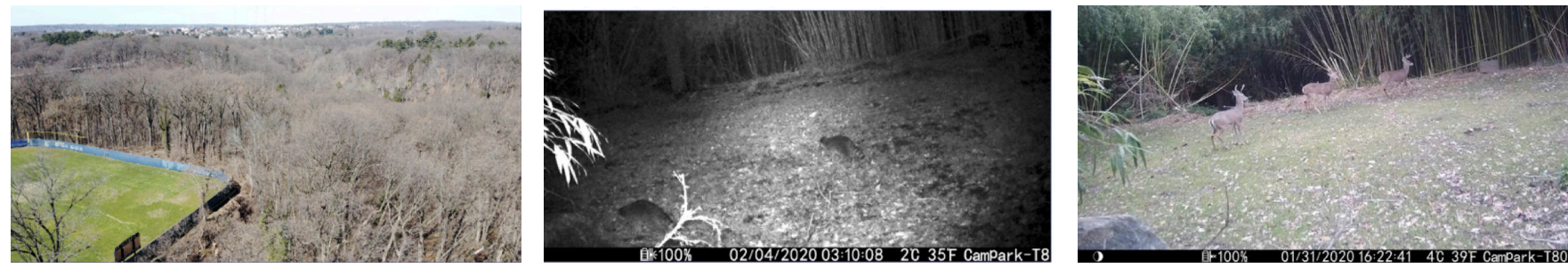

FIGURE 2. Trail camera location and images. (A) Drone view of campus site being monitored. Edge habitat between open fields and wooded areas are often very attractive for wildlife. (B) Nocturnal image of North American raccoons moving through the field of view. (C) Herd of white-tailed deer standing in the grass during daylight hours. The camera shot provides the following information from left to right: moon phase, battery level of the camera, date, time, temperature.

sented their results and articulated the relevance of their research to the undergraduate research poster session hosted virtually in April by the Jefferson College of Life Sciences. The research project design was also presented as a poster at the Sencer Summer Institute 2020, by Dr. Tripepi. Other formal presentations can include thesis presentations, local, regional and national scientific meetings, as well as scientific publications. The research students involved in the Jefferson campus project set up and curate an Instagram page, @Jefferson_wildlife_project, where they share videos and images of the recording to engage the public and students on campus. Venues for outreach and informal dissemination can include student clubs, local nature centers, social media, blogs, or guest appearances in classes.

\section{SUPPLEMENTAL MATERIALS}

Appendix I: Materials

Appendix 2: Sample of data and data presentation

\section{ACKNOWLEDGMENTS}

Publication was made possible in part by support from the Thomas Jefferson University Open Access Fund. The authors have no conflicts of interest to declare.

\section{REFERENGES}

I. Omary MB, Eswaraka J, Kimball SD, Moghe PV, Panettieri RA, Scotto KW. 2020. The COVID-19 pandemic and research shutdown: staying safe and productive. J Clin Invest 130(6):2745-2748.
2. Qiang Z, Obando AG, Chen Y, Ye C. 2020. Revisiting distance learning resources for undergraduate research and lab activities during COVID-19 pandemic. J Chem Educ 97(9): 3446-3449.

3. Wigginton NS, Cunningham RM, Katz RH, Lidstrom ME, Moler KA, Wirtz D, Zuber MT. 2020. Moving academic research forward during COVID-19. Science 368(6496):I190-II92.

4. Steenweg R, Hebblewhite M, Kays R, Ahumada J, Fisher JT, Burton C, Townsend SE, Carbone JC, Rowcliffe M, Whittington J, Brodie J, Royle A, Switalski A, Clevenger AP, Heim N, Rich LN. 2017. Scaling up camera traps: monitoring the planet's biodiversity with networks of remote sensors. Front Ecol Environ I5(I):26-34.

5. Bocsi T, Warren, PS, Harper RW, DeStefano S. 2018. Wildlife habitat management on college and university campuses. Cities Environ II(I):I.

6. Shapiro C, Moberg-Parker J, Toma S, Ayon C, Zimmerman H, Roth-Johnson EA, Hancock SP, Levis-Fitzgerald M, Sanders ER. 20I5. Comparing the impact of course-based and apprentice-based research experiences in a life science laboratory curriculum. J Microbiol Biol Educ 16(2):186-197.

7. Mitchell N, Triska M, Liberatore A, Ashcroft L, Weatherill R, Longnecker N. 2017. Benefits and challenges of incorporating citizen science into university education. PLOS One I2(II). https://doi.org//0.137I/journal.pone.0186285

8. Lopatto D. 2007. Undergraduate research experiences support science career decisions and active learning. CBE Life Sci Educ 6:297-306.

9. Eagan K, Hurtado S, Chang MJ, Garcia GA, Herrera FA, Garibay JC. 2013. Making a difference in science education: the impact of undergraduate research programs. Am Educ Res J 50:683-713.

10. Laursen S, Hunter AB, Seymour E, Thiry H, Melton G. 2010. Undergraduate research in the sciences: engaging students in real science. John Wiley \& Sons, Hoboken, NJ. 